\title{
Statins, coenzyme Q10 and diabetes type 2
}

\section{Ginter E}

Slovak Medical University (emeritus), Bratislava, Slovakia. ginter.emil@mail.t-com.sk

In our review on statins, published in BLL (1) we described the side effects of statins that reduce endogenous production of coenzyme Q10 (Q10). Regarding the side effects of statins, a myopathy marked with muscle pain occurs in patients prescribed high statin dose. This muscle disorder is related to statin inhibition of farnesyl phosphate resulting in the decrease of Q10. Such a decrease was observed both in experimental animals (2) and humans (3). It was suggested that a deficiency of Q10 in the pancreas could impair bioenergetics, the generation of ATP, and the biosynthesis of insulin (4). In diabetes, $\mathrm{CoQ}_{10}$ deficiency may be linked to impaired beta-cell function and the development of insulin resistance (5). Low plasma $\mathrm{CoQ}_{10}$ concentrations have been negatively correlated with poor glycaemic control and diabetic complications.

More recent studies have shown that statins increased the risk of type 2 diabetes. Large scale meta-analyses of statin trials support the concept of a diabetogenic effect of statins (6). Recently an

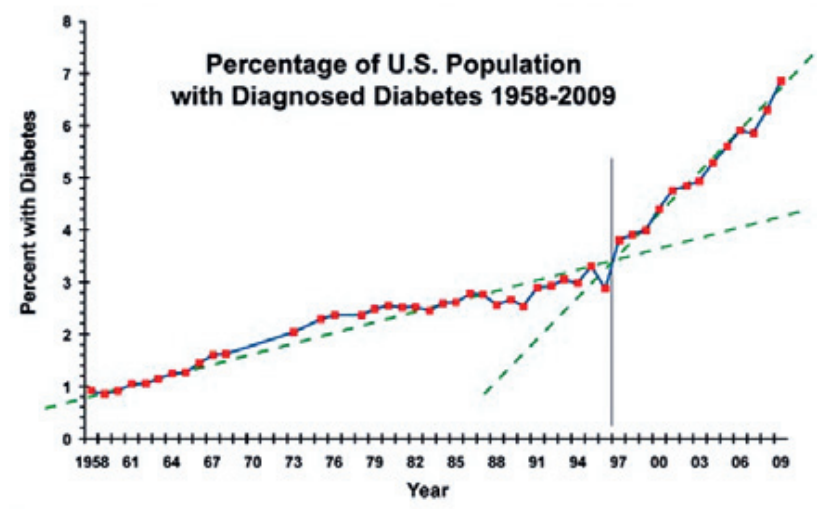

Fig. 1. Sudden increase of diabetes prevalence in USA. According to CDC's Division of Diabetes Translation. National Diabetes Surveillance System. increased risk of new onset treated diabetes was found in patients treated with statins (7). Due to aggressive marketing efforts statin use started to increase dramatically. In USA the rate of diabetes gradually increased from 1958 to 1996 . Then around 1997 the rate of diabetes suddenly jumps by 500 percent (Fig. 1). Did current obesity epidemic suddenly increase by 500 percent in 1997 ? No, but something else happened in the mid to late 1990s to accelerate this trend. Statin use seems to be the most likely suspect. Although it does appear that statins may increase the diabetes, this should not stop diabetics from using of statins, as this small risk is outweighed by the substantial reduction in cardiovascular events. On the other side, caution should be taken in prescribing statins for primary prevention among people at low cardiovascular risk.

\section{References}

1. Ginter E, Simko V. Statins: the drugs for the 21 st century? Bratisl Lek Listy 2009; 110 (10): 664-668.

2. Kucharska J, Ulicna O, Gvozdjakova A et al. Effects of atorvastatin on heart mitochondrial function and coenzyme Q content in the experiment. Bratisl Lek Listy 2011; 112: 603-604.

3. Lamperti C, Naini AB, Lucchini V et al. Muscle coenzyme Q10 level in statin-related myopathy. Arch Neurol 2005; 62: 1709-1712.

4. Kishi T, Kishi H, Watanabe $\mathbf{T}$ et al. Bioenergetics in clinical medicine. XI. Studies on coenzyme Q and diabetes mellitus. J Med 1976; 7: 307-321.

5. Chew GT, Watts GF. Coenzyme Q10 and diabetic endotheliopathy: oxidative stress and the 'recoupling hypothesis' QJM 2004; 97: 537-548.

6. Sattar N, Taskinen MR. Statins are diabetogenic - myth or reality? Atheroscler Suppl 2012; 13 (1): 1-10.

7. Zaharan NL, Williams D, Bennett K. Statins and risk of treated incident diabetes in a primary care population. Br J Clin Pharmacol 2013; 75 (4): $1118-1124$. 